LICENÇA CC BY: Artigo distribuído sob os termos

Creative Commons, permite uso e distribuição irrestrita em qualquer meio desde que o autor credite a fonte original.

\section{DERMEVAL SAVIANI E A POLÍTICA EDUCACIONAL NO BRASIL}

DERMEVAL SAVIANI AND EDUCATIONAL POLICY IN BRAZIL DERMEVAL SAVIANI Y LA POLÍTICA EDUCATIVA EN BRASIL

Raquel de Almeida Moraes ${ }^{1}$

${ }^{1}$ Faculdade de Educação, Universidade de Brasília, Brasília, DF, Brasil.

Artigo recebido em: 14/01/2020

Aprovado em: 29/10/2020

Resumo: O objetivo do artigo é divulgar os resultados de pesquisa sobre a importância de Dermeval Saviani para a política educacional brasileira. Mediante abordagem metodológica fundamentada na perspectiva materialista-dialética, recorreu-se à pesquisa bibliográfica nas bases de dados da internet com os descritores Saviani e Política Educacional. Dentre os resultados, assinala a ausência deste teórico nos autores que produzem conhecimentos sobre política educacional no Brasil. No entanto, a pesquisa constatou que Dermeval Saviani é produtor de conhecimento sobre a política educacional, contribuindo para o seu avanço; é articulador de ações em política educacional, contribuindo para a superação dos problemas, além de ser propositor de uma política educacional contra hegemônica educacional via Pedagogia Histórico-Crítica.

Palavras-Chave: Política Educacional; Política Educacional Contra hegemônica; Dermeval Saviani.

Abstract: This article aims to disseminate the results of research on the importance of Dermeval Saviani for Brazilian Educational Policy. Through a methodological approach based on the materialist-dialectical perspective, we conducted a literature review on Internet databases, using the keywords Saviani and Educational Policy. The results show that his theory is absent among the authors who produce knowledge about Educational Policy in Brazil. However, the research also found that Dermeval Saviani is a producer of knowledge on educational policy, contributing to its advancement; He is the articulator of actions in educational policy, contributing to overcoming educational problems, as well as being a proponent of a counterhegemonic educational policy via Historical-Critical Pedagogy.

Keywords: Educational Policy; Counter-hegemonic Educational Policy; Dermeval Saviani.

Resumen: El objetivo del artículo es difundir los resultados de la investigación sobre la importancia de Dermeval Saviani para la Política Educativa brasileña. A través de un enfoque metodológico basado en la perspectiva materialista-dialéctica, recurrimos a la investigación bibliográfica en bases de datos de Internet con los descriptores Saviani y Educational Policy. Entre los resultados, señala la ausencia de este teórico en los autores que producen conocimiento sobre Política Educativa en Brasil. Sin embargo, la investigación encontró que Dermeval Saviani es un productor de conocimiento sobre política educativa, contribuyendo a su avance; Es el articulador de acciones en 
política educativa que contribuyen a la superación de problemas educativos además de ser el defensor de una política educativa contrahegemónica a través de la pedagogía históricocrítica.

Palabras clave: Política educativa; Política educativa contrahegemónica; Dermeval Saviani.

\section{Introdução}

Dermeval Saviani é professor emérito da Unicamp, ganhador dos prêmios Jabuti e CNPq de Literatura e Ciência, com uma dezena de publicações entre artigos e livros. Sua obra vem sendo estudada e aplicada tanto nos Currículos de Formação de Professores nas disciplinas de Didática, História e Filosofia da Educação, como na Política Educacional.

Sua proposta educativa é tributária da concepção dialética, especificamente na versão do materialismo histórico, tendo fortes afinidades, no que se refere às suas bases psicológicas, com a psicologia histórico-cultural desenvolvida pela "Escola de Vigotski". Para este educador, cientista e filósofo, a educação é entendida como o ato de produzir, direta e intencionalmente, em cada indivíduo singular, a humanidade que é produzida histórica e coletivamente pelo conjunto dos homens. Em outros termos, isso significa que a educação é entendida como mediação no seio da prática social global (NEDER; MORAES, 2017).

Saviani é Líder do Grupo do CNPq: História, Sociedade e Educação no Brasil - HISTEDBR, o qual se define pelo amplo campo de investigação no qual a temática da educação é trabalhada desde a História, com os métodos e as teorias próprios e característicos dessa área do conhecimento.

Conforme site do HISTEDBR, a denominação "História, Sociedade e Educação" se vincula a um entendimento que remete ao historiador - aquele que exercita a História com seus métodos, teorias e instrumentais - a tarefa de dedicar-se, entre outros objetos e problemas de investigação, à educação que, por sua vez, não é mera abstração, mas é social, geográfica e historicamente determinada. Assim, o Grupo de Estudos e Pesquisas "História, Sociedade e Educação no Brasil/HISTEDBR" é um coletivo nacional de pesquisa que tem articulado a participação de Grupos de Trabalho da área de História da Educação em vários estados brasileiros. Se é notória sua importância nas áreas de História da Educação, de Filosofia da Educação e Didática (verificado pelo número de publicações de outros autores a respeito desse autor), consultando a base de dados do Google em 07/05/2019 com os descritores: Dermeval Saviani e Política Educacional, constatou-se a presença de obras do próprio autor. Refinando mais a busca para as bases de dados do Google Acadêmico e Periódicos da Capes em 07/05/2019, o mesmo fato ocorreu, comprovando-se escassez de registros de outros autores em diálogo com o Saviani no quesito política educacional e seus temas decorrentes.

Para expor os resultados de nossa pesquisa sobre esse autor, o presente artigo está dividido em três tópicos: metodologia, resultados (autor e outros autores) e discussão, seguido das considerações finais. 


\section{Metodologia}

Esta pesquisa é fundamentada na perspectiva filosófica do materialismo-dialético quanto ao método. Para Marcondes (2004), Marx se insere na perspectiva crítica do pensamento moderno iniciada por Descartes e que prossegue com Bacon, Kant e Hegel.

A seu ver, uma importante noção desenvolvida por Marx é a ideologia. Criada pelo pensador iluminista Antoine Destut de Tracy com outros "ideólogos", a palavra tinha o significado de ciência das ideias. Para Marx, no entanto, essa "ciência das ideias" tinha um sentido negativo ao produzir uma "falsa consciência", distorcendo e mascarando a realidade, "uma realidade opressora, que faz com que seu lado negativo seja ocultado." (MARCONDES, 2004 , p. 230).

Assim como não se julga um indivíduo pela ideia que ele faz de si próprio, não se poderá julgar uma tal época de transformação pela sua consciência de si, é preciso, pelo contrário, explicar esta consciência pelas contradições da vida material, pelo conflito que existe entre as forças produtivas sociais e as relações de produção. (MARX, 1971, p. 29).

A tarefa da filosofia crítica para Marcondes é, portanto: "desmascarar a realidade, revelar o processo pelo qual se produz, fazendo com que perca seus efeitos, desfazendo as ilusões que gera." (MARCONDES, 2004, p. 231).

Para Marx (2008, p. 47), o "método de vida material condiciona o processo de vida social, política e intelectual. Não é a consciência dos homens que determina o seu ser; ao contrário, é o seu ser social que determina sua consciência". E, ainda: "É preciso, ao contrário, explicar essa consciência pelas contradições da vida material, pelo conflito que existe entre as forças produtivas sociais e as relações de produção." (MARX, 2008, p. 48).

Marx (1986, p. 72) argumenta que a classe dominante produz ideias e representações produtos da consciência - que não correspondem à vida material e que, ao não corresponderem à vida real, tornam-se ideologia, pois "os homens e suas relações aparecem invertidos como numa câmara escura".

Tendo em vista esses fundamentos teóricos, recorreu-se à pesquisa bibliográfica nas bases de dados da internet utilizando os descritores Saviani e Política Educacional Saviani. Para a análise desses materiais, utilizou-se o referencial de análise do discurso de Fiorin (2007).

Fiorin (2007, p.51) assinala que a "análise, em síntese, não se interessa pela 'verdadeira' posição ideológica do enunciador real, mas pelas visões de mundo dos enunciadores (um ou vários) inscritos no discurso", de modo a fazer uma avaliação crítica.

Discurso, para esse autor, é entendido como a combinatória de elementos linguísticos utilizada pelos falantes para exprimir seus pensamentos, refletir e agir sobre o mundo. Partindo da hipótese de que o discurso possui organização e regularidade, Fiorin (2007) afirma que o discurso está estruturado por uma sintaxe e uma semântica. Da sintaxe do discurso fazem parte os processos de estruturação que organizam as estratégias argumentativas utilizadas pelo enunciador para criar "efeitos de verdade" e persuadir seus enunciatários. Da semântica 
discursiva fazem parte os conteúdos investidos nos moldes sintáticos abstratos, que refletem, por meio de formações discursivas, o conjunto de temas e figuras que refletem a maneira de ver o mundo em determinada classe dentro de uma sociedade. Assim, uma formação social possui várias frações de classes, e a cada uma delas corresponde uma formação ideológica e uma formação discursiva. Para Fiorin (2007), a visão de mundo de uma classe social e as figuras concretizam os temas que circulam nas classes de uma sociedade.

Em vista disso, procurou-se apreender as figuras (sentidos) que concretizam os temas que emergem da Política Educacional por meio do levantamento dos títulos de suas publicações presentes em seu currículo na Plataforma Lattes, no Conselho Nacional de Pesquisa Científica (CNPq).

Na pesquisa histórica, um dos maiores desafios é unir as fontes, tanto documentais como orais aos fatos nos tempos e nos espaços delimitados. Vieira Pinto (1969) assinala que a contradição dialética é uma categoria central na lógica concreta. A seu ver, a contradição é a "prova da veracidade da ideia, de sua boa qualidade enquanto reflexo do objeto existente, que menciona". (VIEIRA PINTO, 1969, p. 189). (grifo nosso)

\section{Resultados}

\subsection{DO AUTOR}

A pesquisa sobre a importância de Dermeval Saviani para a política educacional brasileira abrangeu tanto a consulta ao seu currículo na Plataforma Lattes do CNPq como a pesquisa de outros autores que estudam a Política Educacional e o incluem nas suas referências nas seguintes bases: Periódicos da Capes e Google.Acadêmico.

Na consulta ao seu Currículo Lattes, buscou-se analisar os títulos dos Artigos, Livros/ Capítulos de Livros e Projetos de Pesquisa a partir da categoria "Política Educacional". Da análise dessa categoria foram recorrentes os seguintes temas, os quais foram distribuídos em ordem decrescente: 
Tabela 1: Produção intelectual quanto à categoria Política Educacional distribuída pelos temas mais recorrentes da obra de Dermeval Saviani

\begin{tabular}{|l|l|l|l|l|}
\hline Temas & Artigos & Livros & $\begin{array}{l}\text { Capítulos de livros } \\
\text { publicados }\end{array}$ & $\begin{array}{l}\text { Projetos de pes- } \\
\text { quisa }\end{array}$ \\
\hline Legislação & 6 & 9 & 1 & 1 \\
\hline Política & 5 & 1 & 3 & --- \\
\hline Sistema & 5 & 3 & 4 & --- \\
\hline Democracia & 3 & 5 & 2 & --- \\
\hline Direito & 2 & ---- & ---- & --- \\
\hline Plano & 2 & 4 & 2 & --- \\
\hline Estrutura & 1 & 3 & ---- & --- \\
\hline Estado & 0 & 1 & 1 & 1 \\
\hline
\end{tabular}

Fonte: Elaboração do autor.

Por fim, foram selecionados dois (2) projetos de pesquisa de cinco (5) existentes no CV Lattes de Saviani, representando 40\% da produção do conhecimento, abordando respectivamente os temas do Estado (1) e Legislação (1).

Reconstrução histórica da escola pública no Brasil (1870-1996)

Descrição: Análise da escola pública no Brasil tendo como referência uma periodização geral da história da escola no Brasil, visando reconstruir a história da educação pública a partir de sua organização institucional traduzida pelo modo como o Estado dispõe os recursos, promovendo a expansão da oferta educacional e sua distribuição no espaço e tempo escolares.

Situação: Concluído; Natureza: Pesquisa.

Alunos envolvidos: Graduação: (2).

Integrantes: Dermeval Saviani - Coordenador.

Número de produções $C, T \& A: 7$

A nova Lei de Diretrizes e Bases da Educação Nacional

Descrição: Estudo analítico e crítico da trajetória da nova LDB, desde a apresentação do primeiro projeto em dezembro de 1988 até sua promulgação em dezembro de 1996.

Situação: Concluído; Natureza: Pesquisa.

Integrantes: Dermeval Saviani - Coordenador.

Número de produções $C, T \& A: 3$ 


\section{2 - Dermeval Saviani e a Política Educacional - outros autores}

Sobre a presença de Saviani na política educacional a partir da visão de outros autores, foram encontrados três (3) artigos:

1 KRAWCZYK, NORA. A historicidade da pesquisa em política educacional: o caso do Brasil. Jornal de Políticas Educacionais, v. 6, p. 3-11, 2013.

2 STREMEL, Silvana; MAINARDES, J. A disciplina Política Educacional em Cursos de Pedagogia no Brasil: primeiras aproximações. JORNAL DE POLÍTICAS EDUCACIONAIS, v. 9, p. 137-155, 2015.

3 MAINARDES, J. Reflexões sobre o objeto de estudo da política educacional. LAPLAGE EM REVISTA, v. 4, p. 186-201, 2018.

O artigo de Krawczyk (2013) situa a influência de Saviani no desenvolvimento da política educacional.

(...) vale citar também a polêmica desencadeada por Dermeval Saviani no livro Escola e Democracia, editado por primeira vez em 1983, onde argumenta sobre a necessidade de uma nova teoria e uma visão alternativa superadora às visões que segundo o autor se acreditavam progressistas, consubstanciadas na Teoria Pedagógica Histórico-Critica. (KRAWCZYK, 2013, p.37).

Em artigo de Stremel \& Mainardes (2015), o livro de Saviani "Nova Lei da Educação: trajetórias limites e perspectivas" consta como a obra mais frequente nos cursos de Política Educacional (STREMEL \& MAINARDES, 2015, p.152). Mas essa informação fica solta e não é retomada. Mainardes et al. $(2015,2018)$ nos levaram à Red de Estudios Teóricos y Epistemológicos en Política Educativa, RELEPE: <http://www.relepe.org/>. Nesse site, é informado que a RELEPE se estrutura nos seguintes eixos de investigação:

1 - Problemáticas e limitações no desenvolvimento da pesquisa em Política Educacional.

2 - Enfoques e perspectivas epistemológicas em Política Educacional.

3 - Metodologias para a análise de Políticas Educacionais.

4 - História do campo da Política Educacional.

5 - Investigação analítica de autores de referência em Política Educacional.

6 - Produção de conhecimento e tomada de decisões em perspectiva epistemológica.

7 - Epistemologia, Política Educacional e realidade latino-americana.

8 - Ensino de Política Educacional e formação de pesquisadores para este campo.

Consultando-se na Biblioteca Temática da RELEPE sobre o eixo 5, há o registro de 54 obras on-line e 32 impressas. No entanto, a obra de Saviani não aparece nesta listagem.

Contraditoriamente, em 2017 Saviani publicou o artigo: "Epistemologias da política educacional: algumas precisões conceituais", na Revista de Estudios Teóricos y Epistemológicos, v. 2, p. 1-5. 
Diante dessa ausência e contradição, questionamos: por que Saviani não se apresenta como referência nos outros estudiosos sobre Política Educacional no Brasil?

No tópico a seguir, faremos algumas ponderações neste sentido.

\section{Discussão}

A ausência ou escassez de autores que citam a produção de um respectivo autor não é sinal de que este mesmo autor não tenha produzido naquele campo específico do conhecimento. É o que sucede, a nosso ver, com o intelectual Dermeval Saviani, pelos argumentos a seguir.

Saviani (2017) define o termo "política" tomando como referência Bobbio (1999), para quem, no sentido amplo e não somente em sentido técnico, esse termo refere-se a "qualquer estudo dos fenômenos e das estruturas políticas, conduzido sistematicamente e com rigor, apoiado em amplo e cuidadoso exame dos fatos expostos com argumentos racionais" (BOBBIO, 1999, p. 164). Acrescentando, ainda, que o "o termo 'ciência' expressa o sentido tradicional de um conhecimento oposto à simples 'opinião', significando que os juízos formulados se baseiam não em crenças ou dados imprecisos, mas nas provas dos fatos." (SAVIANI, 2017, p. 3).

Saviani (2017) também considera válido o argumento de Schmied-Kowarzik (1983, p. 12), de que a ciência política "perdeu qualquer capacidade de influir na práxis política enquanto ciência do conhecimento histórico e sociológico ou ciência expositiva jurídica" (p. 12).

Diante disso, teoriza que,

(...) a formulação da política educacional deve levar em conta, do ponto de vista da forma, isto é, da perspectiva adotada, as determinações políticas ligadas aos mecanismos de poder, à correlação de forças e à legalidade e legitimidade instauradas pela forma de Estado e regime político prevalecentes, do ponto de vista do conteúdo, isto é, do objeto, as referidas políticas devem se pautar pelas exigências educacionais definidas no âmbito da ciência pedagógica. (SAVIANI, 2017, p.4).

Em outro texto, articulando a educação à questão dos direitos, Saviani (2013) critica a divisão tripartite da teoria dos direitos individuais de Marshall (1967): direitos civis, políticos e sociais, por considerá-la formalista. A seu ver:

Com efeito, a educação, para além de se constituir em determinado tipo de direito, o direito social, configura-se como condição necessária, ainda que não suficiente, para o exercício de todos os direitos, sejam eles civis, políticos, sociais, econômicos ou de qualquer outra natureza. (SAVIANI, 2013, p. 744).

E corrobora essa tese afirmando que:

Portanto, a participação ativa nessa sociedade, vale dizer, o exercício dos direitos de todo tipo, pressupõe o acesso aos códigos escritos. Eis porque esse mesmo tipo de sociedade erigiu a escola em forma principal e dominante de educação e advogou a universalização da escola elementar como forma de converter todos os indivíduos em cidadãos, isto é, em sujeitos de direitos e deveres. (SAVIANI, 2013, p.755).

Um outro argumento é que Saviani não só produziu conhecimento sobre Política Educacional como também participou de sua elaboração mediante a proposição de legislação para sua regulação. Na edição revista, atualizada e ampliada da obra "A Lei da Educação" em 
2019, Saviani assim se manifesta:

Eis que o autor deste livro foi convidado pela diretoria da Anped para proferir conferência sobre o tema "Em direção às novas diretrizes e bases da educação" em sua X Reunião Anual realizada em Salvador, o que de fato ocorreu em 13 de maio de 1987.

No final de 1987, ao definir-se a pauta do número 13 da Revista da ANDE, decidiu-se que o tema central seria a nova LDB. Novamente este autor, que à época integrava a equipe editorial da revista, foi chamado a redigir um artigo sobre o tema. Tinha início a elaboração do projeto original da nova Lei de Diretrizes da Educação Nacional.

(...) Promulgada a Constituição Federal em 5 de outubro de 1988, em dezembro do mesmo ano, o deputado Octávio Elísio apresentou na Câmara Federal o projeto de lei que recebeu o número 1.158-A/1988, fixando as diretrizes e bases da educação nacional.

O projeto em pauta estava constituído pelo texto integral da proposta acima referida, ampliado no Título IX - Dos recursos para a educação, que passou de 7 para 19 artigos. (SAVIANI, 2019, p.43-44; 52).

Como se constata pelo registro anterior, foi a partir de texto elaborado com contribuição da sociedade educacional brasileira que tramitou a segunda LDB. Mas seu desfecho não foi democrático, como ele aspirava:

Desta vez, a circunstância da elaboração de uma nova LDB, propiciada pela Constituição de 1988 , criou novas esperanças que resultaram frustradas pela ofensiva neoconservadora que logrou tornarse politicamente hegemônica a partir de 1990. (SAVIANI, 2019, p.295) (grifo nosso).

Um outro argumento a favor de sua importância é que, além de produzir e praticar o conhecimento em política educacional (coerente com o que propõe como tarefa epistemológica fundamental), Saviani também se destaca na construção de uma proposta contra hegemônica à dominação política que a sociedade dividida em classes impõe à humanidade: "o dominado não se liberta se ele não vier a dominar aquilo que os dominantes dominam. Então, dominar o que os dominantes dominam é condição de libertação." (SAVIANI, 2007, p. 55).

Para este educador, cientista e filósofo, a educação é entendida como o ato de produzir, direta e intencionalmente, em cada indivíduo singular, a humanidade que é produzida histórica e coletivamente pelo conjunto dos homens. Em outros termos, isso significa que a educação é entendida como mediação no seio da prática social global.

Saviani (2007, p. 170) teoriza que as propostas pedagógicas contra hegemônicas são entendidas como aquelas que se inserem dentro das tendências pedagógicas educacionais, cujas orientações "(...) não apenas não conseguiram torna-se dominantes, mas que buscam intencional e sistematicamente colocar a educação a serviço das forças que lutam para transformar a ordem vigente visando instaurar uma nova sociedade."

As propostas contra hegemônicas emergem do Golpe Militar no Brasil (1964-1985). Para Lopez \& Mota (2008, p. 798), "o que ocorreu em 1964 pode ser definido como uma contrarrevolução preventiva, na tradição da história do Brasil que remonta à revolução e contrarrevolução da Independência. Ou, mais simplesmente, um Golpe de Estado".

Citando Carlos Marchi (apud Lopez \& Mota, p. 798): 
Foi um golpe de Estado clássico, do tipo que pontuou a história dos países subdesenvolvidos, embora, no caso, aplicado a um país que ganhava complexidade econômica e social (...). Ali chegaram a um ponto crucial de ebulição dois modelos arcaicos e autoritários - um de esquerda, com raízes populistas e corporativas, outro de direita, com vínculo liberal selvagem excludente.

Segundo Lopez \& Mota (2008, p. 799), o Golpe foi imediatamente apoiado pelo governo americano, que destacou porta-aviões e navios de guerra para os portos brasileiros, a fim de, em caso de necessidade, auxiliar no combate às forças locais do "comunismo".

Para Saviani (2007), a Revolução de 1964 trouxe ruptura no nível político, mas não no nível econômico. "Ausência de 'revolução social' e 'mudança política radical', eis a conclusão a que chegam analistas de variadas tendências sobre a Revolução de 1964". (SAVIANI, 2007, p. 362).

Na década de 1950, vigorava o modelo econômico de "substituição das importações" ou constituição do Departamento I da Economia (bens de produção). A industrialização surgiu como uma bandeira em torno da qual se uniram as diferentes forças sociais. Industrialismo e nacionalismo, assim, se confundiram.

No entanto, no início dos anos 1960, uma contradição veio à tona: o modelo econômico tornava-se cada vez mais internacionalizado versus uma ideologia política nacional desenvolvimentista. Tal contradição, segundo Saviani, é encontrada latente em todo o processo desenvolvimentista. Ela foi se impondo à medida que a industrialização avançava, até emergir por inteiro, quando cessou o modelo de "substituição de importações". Em 1969, o País já não dependia de importação de manufaturas, não sendo mais preciso lutar por ela.

Se, para os empresários nacionais e internacionais e as classes intermediárias, a industrialização era um fim em si mesmo, para o operariado e as forças da esquerda ela era apenas uma etapa. Por isso, atingida a meta, a burguesia buscou consolidar seu poder, ao passo que as forças da esquerda levantaram nova bandeira: nacionalização das empresas estrangeiras, controle da reserva de lucros, reformas sociais, etc. Tais objetivos eram decorrência da ideologia política do nacionalismo desenvolvimentista, que passou a entrar em conflito com o modelo econômico então vigente: o internacionalismo.

Neste sentido, a ideologia do nacionalismo desenvolvimentista entrou em crise e foi substituída pela ideologia da Doutrina da Segurança Nacional, elaborada no seio da Escola Superior de Guerra. Portanto, a Revolução de 1964 representou uma ruptura somente no plano político e não no nível socioeconômico.

Para Saviani (2007), com o advento do regime militar, o lema positivista "Ordem e Progresso" inscrito na bandeira metamorfoseou-se em "segurança e desenvolvimento". O positivismo que tinha inspirado o movimento republicano volta novamente ao cenário político brasileiro.

Shiroma et al. (2011) argumentam que, ao longo do século XX, as reformas do ensino caracterizam uma modernização administrada. As reformas do regime militar foram balizadas pelas recomendações advindas das agências internacionais e pelos relatórios vinculados ao governo norte-americano (Relatório Atcon) e ao Ministério da Educação Brasileiro (Relatório 
Meira Mattos), no intuito de o país incorporar compromissos assumidos pelo governo na Carta de Punta del Este (1961) e no Plano Decenal de Educação da Aliança para o Progresso Acordos MEC-USAID.

Segundo Dario do Carmo Rocha (2005), na Carta de Punta del Este estão presentes as ideias positivistas como regra para as políticas públicas, e que serviram de inspiração para justificar as melhores condições de vida e a justiça social como resultado somente do trabalho do homem livre, cujo seu espírito é patrimônio da civilização americana.

Para Shiroma et al. (2011), a Reforma dos anos 1960 e 1970 estava voltada para o desenvolvimento, que significa, para o regime, "uma educação para a formação do capital humano, vinculação entre educação e mercado de trabalho, modernização de hábitos de consumo, integração da política educacional aos planos gerais do desenvolvimento e segurança nacional, defesa do Estado, repressão e controle político ideológico da vida intelectual e artística do país". (SHIROMA et al., 2011, p. 29).

Saviani (2007) argumenta que o continuísmo econômico também prevaleceu na educação, tendo as leis reformistas a orientação de ajustarem o ensino ao direcionamento político então vigente. Daí pôde-se entender melhor os convênios MEC/USAID que subsidiaram essas reformas, foi a abertura do País ao internacionalismo como regra de orientação da política educacional que visou mais "ideologizar" do que "ensinar".

A pedagogia tecnicista tem por pressuposto a neutralidade científica e é inspirada nos princípios da racionalidade, da eficiência e da produtividade, advogando a reorganização do processo educativo de maneira que o torne objetivo e operacional. "De modo semelhante ao que ocorreu no trabalho fabril, pretende-se a objetivação do trabalho pedagógico". (SAVIANI, 2007, p. 379).

Inspirada na Teoria do Capital Humano $(\mathrm{TCH})$, a educação tecnicista é considerada como um investimento para os planos econômicos globais. O trabalho humano, quando qualificado pela educação, é um dos principais meios do aumento de produtividade, dos lucros do capital e, consequentemente, em algum momento vai gerar benefício econômico também para o próprio indivíduo (SCHULTZ, 1962).

Para Saviani (2007), se na pedagogia tradicional a iniciativa cabia ao professor, que era, ao mesmo tempo, o sujeito do processo, o elemento decisivo e decisório; e se na pedagogia nova a iniciativa se desloca para o aluno, situando-se o nervo da ação educativa na relação professor-aluno, portanto, relação interpessoal, intersubjetiva

\footnotetext{
(...) na pedagogia tecnicista o elemento principal passa a ser a organização racional dos meios, ocupando o professor e o aluno posição secundária, relegados que são à condição de executores de um processo cuja concepção, planejamento, coordenação e controle ficam a cargo de especialistas supostamente habilitados, neutros, objetivos, imparciais. A organização do processo converte-se na garantia da eficiência, compensando e corrigindo as deficiências do professor e maximizando os efeitos de sua intervenção. (SAVIANI, 2007, p. 380).
}

A concepção analítica refere-se à clareza e à consistência dos enunciados relativos aos fenômenos e não aos próprios fenômenos. A ela cabe fazer a "assepsia da linguagem, 
depurá-la de suas inconsistências e ambiguidades. Não é sua tarefa produzir enunciados que se constituam em diretrizes teóricas e muito menos práticas." (SAVIANI, 2007, p. 382).

Segundo Saviani (2007), a pedagogia tecnicista e a analítica diferem-se no plano das consequências, mas têm a mesma matriz de pressupostos: objetividade, racionalidade e neutralidade colocados com condição de cientificidade. A visão crítico reprodutivista em educação emerge nesse momento fazendo a crítica da educação dominante, pondo em evidência as reais funções da política educacional que eram acobertadas pelo discurso políticopedagógico oficial. As principais referências dessa visão são a "teoria do sistema de ensino enquanto violência simbólica, teoria da escola enquanto aparelho ideológico do Estado" e "teoria da escola dualista." (SAVIANI, 2007, p. 391-2).

A partir da década de 1990 emerge a pedagogia produtivista, tendo como fundamento a ordem econômica denominada pós-fordista e pós-keynesiana. Assentando-se na exclusão, pressupõe que não há lugar para todos. As bases pedagógicas da pedagogia produtivista são o aprender a aprender, cuja ênfase recai na aprendizagem do estudante. Isso gera um retorno às ideias escolanovistas, daí o neoescolanovismo. "Estimulando a competição e buscando maximizar a produtividade, isto é, o incremento do lucro, a extração da mais valia, ela rege-se por uma lógica que estabelece o predomínio do trabalho morto (capital) sobre o trabalho vivo, conduzindo à exclusão deliberada de trabalhadores". (SAVIANI, 2007, p. 429)

Em oposição a essas distintas pedagogias hegemônicas, a Pedagogia Histórico-Crítica vem sendo construída como proposta contrária à hegemonia pedagógica e à política dominante. O artigo de Krawczyk (2013) assinala essa influência de Saviani no desenvolvimento da política educacional numa perspectiva contra hegemônica.

\section{Considerações finais}

Da análise dos dados do CV Lattes de Dermeval Saviani em torno da categoria "política educacional", percebe-se que:

1. A produção sobre Política Educacional de Saviani está concentrada em livros (33,80\%), estando empatadas as produções de capítulos de livros (16,88\%) e artigos (16,55\%).

2. Comparando-se os temas dessas produções com os projetos de pesquisa sobre Política Educacional, percebe-se coerência e persistência na temática da democracia e do direito à educação na legislação brasileira que o Estado tem que oferecer à população desde a infância até a pós-graduação. Para isso, o autor argumenta sobre a necessidade de se implantar o Sistema Nacional de Educação e implementar o Plano de Desenvolvimento da Educação, de modo a que as gerações tenham de fato acesso ao conhecimento acumulado pela humanidade.

3. As citações sobre Saviani, no Google Acadêmico, seguem uma trajetória ascendente, tendo uma maior expressão a partir de 2014. 
Figura 1. Citações de Saviani no Google Scholar

$\times \quad$ Citações por ano

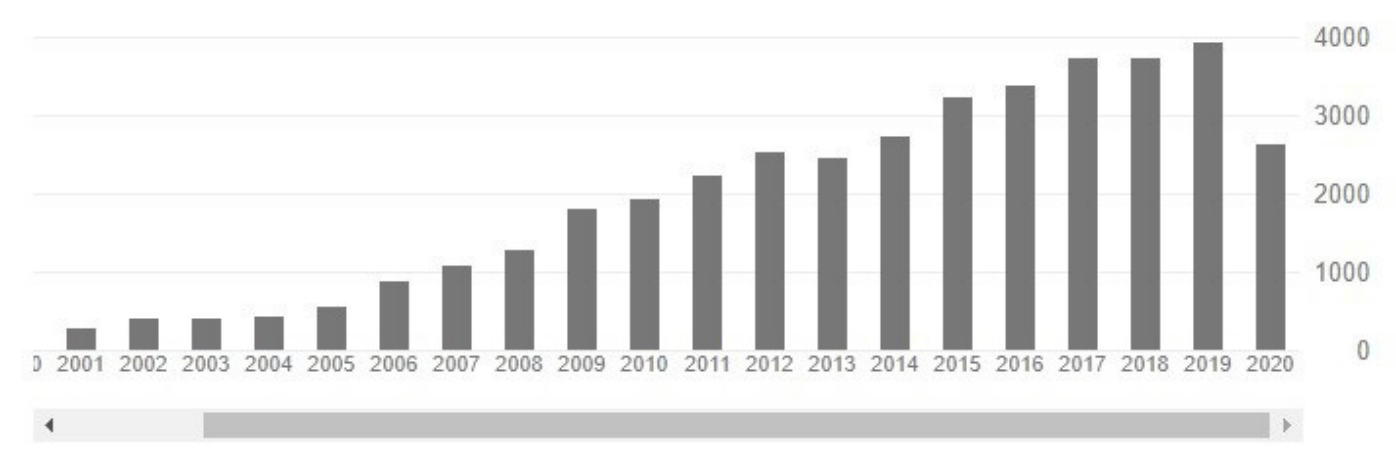

Fonte: Google Acadêmico <https://scholar.google.com.br/citations? user=w3xBeJcAAAAJ\&hl=ptBR\#d=gsc_md_hist>Acesso em 01/08/19.

Considerando o que foi discutido no tópico anterior sobre a contradição que é a quase ausência de Dermeval Saviani como teórico em Política Educacional nos autores que produzem conhecimentos sobre esse campo, pensamos que sua importância para a política educacional brasileira pode ser sintetizada com três assertivas: 1) Produtor de conhecimento sobre a política educacional, contribuindo para o seu avanço; 2) Articulador de ações em política educacional, contribuindo para a superação dos problemas educacionais; 3) Propositor de uma política educacional contra hegemônica via Pedagogia Histórico-Crítica.

\section{Referências}

BOBBIO, N. "Verbete Ciência Política". In: BOBBIO, N.; MATTEUCCI, N. \& PASQUINO, G. Dicionário de política. 12. ed. Brasília: Ed. UnB, 1999. p. 164-169.

FIORIN, J. L. Linguagem e Ideologia. Ed. Ática: São Paulo, 2007.

KRAWCZYK, N. A historicidade da pesquisa em política educacional: o caso do Brasil. Jornal de Políticas Educacionais, v. 6, p. 3-11, 2013.

LOPEZ, A.; MOTA, C. G. História do Brasil. Uma interpretação. Rio de Janeiro: Ed. 34, 2015.

MAINARDES, J. Reflexões sobre o objeto de estudo da política educacional. LAPLAGE EM REVISTA, v. 4, p. 186-201, 2018.

MARCONDES, D. Iniciação à História da Filosofia. Dos Pré-Socráticos a Wittgenstein. Rio de Janeiro: Jorge Zahar Editor, 2004.

MARX, K. Contribuição para a crítica da economia política. São Paulo: Expressão Popular, 2008.

MARX, K; ENGELS, F. Ideologia Alemã. São Paulo: Hucitec, 1986. 
NEDER, R. T.; MORAES, R. A. Para onde vai a política de ciência \& tecnologia no Brasil? 1. ed. Uberlândia: Navegando Editora, 2017.

ROCHA, D. C. A CARTA DE PUNTA DEL ESTE: AS IDÉIAS POSITIVISTAS NAS REFORMAS EDUCACIONAIS E NO PLANO DE SEGURANÇA NACIONAL ORQUESTRADAS NA DÉCADA DE 60. Anais do II Seminário Nacional de Políticas Sociais no Brasil. Unioste, Campus de Cascavel, 13 a 15 de outubro de 2005.

SAVIANI, D. História das Ideias Pedagógicas no Brasil. Campinas: Autores Associados, 2007.

SAVIANI, D. Vicissitudes e perspectivas do direito à educação no Brasil: abordagem histórica e situação atual. Educação \& Sociedade (Impresso), v. 34, p. 743-760, 2013.

SAVIANI, D. Epistemologias da política educacional: algumas precisões conceituais. Revista de Estudios Teóricos y Epistemológicos, v. 2, p. 1-5, 2017.

SAVIANI, D. A lei da educação. 13. ed. Campinas: Autores Associados, 2019.

SCHULTZ, T. O valor econômico da educação. Rio de Janeiro: Zahar, 1962.

SHIROMA, E. et al. Política Educacional. Rio de Janeiro: Lamparina, 2011.

STREMEL, S.; MAINARDES, J. A disciplina Política Educacional em Cursos de Pedagogia no Brasil: primeiras aproximações. JORNAL DE POLÍTICAS EDUCACIONAIS, v. 9, p. 137-155, 2015.

VIEIRA PINTO, Á. Ciência e Existência. Problemas Filosóficos da Pesquisa Científica. Rio de Janeiro: Paz e Terra, 1969.

1 Endereço para acessar o CV de Saviani: http://lattes.cnpq.br/2205251281123354 ID Lattes: 2205251281123354. Última atualização do currículo em 28/01/2019. Acesso em: $31 / 07 / 2019$. 